\title{
Angiosarcoma of the scalp: a case report
}

\author{
Justyna Wittych, MScl, Pawel Banatkiewicz, MD², Marta Wachowicz, MSc', Dorota Pruska-Pich, MSc', \\ Prof. Stanislaw Mitura, DSc, PhD³, Iwona Gisterek, MD, PhD2,3 \\ IMedical Physics Department, International Oncotherapy Centre Koszalin, Euromedic, Poland, ${ }^{2}$ Radiotherapy Department, International \\ Oncotherapy Centre Koszalin, Euromedic, Poland, ${ }^{3}$ Biomedical Engineering Department, University of Technology, Koszalin, Poland
}

\begin{abstract}
Purpose: The aim of this paper is to report the treatment of angiosarcoma of the scalp. High-dose-rate (HDR) brachytherapy with an individual mold applicator is presented.

Case description: A case of a 75-year-old male will be presented with multicentric lesions over the scalp in the temple and crown region. Biopsy diagnosis was angiosarcoma of the scalp, nonoperable. The patient was qualified for chemotherapy combined with radiotherapy.

Discussion: Angiosarcoma of the scalp is a very aggressive tumor. The main aim of the treatment of angiosarcoma is local control of the tumor. Most cases are treated with wide excision surgery. The use of surgery with adjuvant radiotherapy or chemotherapy is recommended in some cases. Chemotherapy and radiotherapy are suggested in the recurrent or extensive lesions with regional or distant metastasis. Radiation therapy can be realized with external beam therapy or brachytherapy. High-dose-rate brachytherapy is an effective, adequate, well tolerated by patients treatment method. In every case, an individual approach is needed.

Conclusions: The HDR brachytherapy technique is useful and practicable. The advantages of brachytherapy are: targeted dose distribution, low integral dose, and short time of treatment. The mold HDR brachytherapy treatment using an individual applicator was an appropriate tool for the presented patient.

J Contemp Brachytherapy 2014; 6, 2: 208-212

DOI: $10.5114 / j \mathrm{cb} .2014 .43183$
\end{abstract}

Key words: angiosarcoma, HDR brachytherapy, mold applicator.

\section{Purpose}

Angiosarcoma is one of the rarest soft tissue tumors in adults. It is only $1 \%$ of the all sarcomas registered in that population [1]. It can occur in all parts of the body [1-4], according to Ruka et al. in more than $50 \%$ in limbs, 35\% in the region of peritoneum, and about $10 \%$ of the head and neck region in Polish population [1]. Angiosarcoma of the scalp is a rare, aggressive, and difficult to treat subtype of that tumor $[2,3,5]$. This kind of soft tissue sarcoma varies significantly in the clinical stage and progression [6]. It arises from the endothelial cells, varying from well differentiated (low-grade) to poorly differentiated (highgrade) tumors $[2,7,8]$. Both types are associated with extensive local growth. Its presentation varies from a small plaque to multifocal nodules. Microscopically, the first one involves the dermis while the second one may invade into deeper structures [8]. According to Mark et al., [2] the grade of the tumor has the influence on 5-year disease free survival. Some authors have found that prognosis is independent of grade in angiosarcoma $[8,9]$.

Tumor size may affect prognosis $[2,5,8,9]$. Some of authors analyzed tumor size and reported a statistically significant correlation between the size of tumor and the survival rate. Tumors less than $5 \mathrm{~cm}$ in diameter are associated with a significantly better prognosis than larger lesions $[5,8,9]$. Ruka et al. [1] provide the treatment recommendation of soft tissue sarcoma. Radical surgery alone is an essential modality in cases with lesions less than $5 \mathrm{~cm}$, superficial, and low grade (stage IA) $[1,4,5,9,10]$. A wide surgical excision into histological negative margins is necessary and it has a big influence on the prognosis. In cases with stage IB, IIA, IIB, and IIC, postoperative radiation therapy is recommended [1-4]. There is no consensus on whether the external beam therapy should be combined with brachytherapy or given alone, or whether one modality is sufficient or not $[1,4,11,12]$. In stage III patients (high-grade tumors G3-G4, size more than $10 \mathrm{~cm}$, no metastases), chemotherapy and radiotherapy before the surgery is suggested [1]. In stage IV cases, chemotherapy is recommended [1]. The role of chemotherapy in angiosarcoma is poorly defined [2,5]. Some reports have been issued, but not established data [13-15]. There are not many papers about angiosarcoma of the scalp $[3,8,9,11,16]$. However, the use of external beam therapy with high-dose-rate (HDR) brachytherapy in extensive angiosarcoma of the scalp has been reported [16]. High-dose-rate brachyther-

\footnotetext{
Address for correspondence: Justyna Wittych, MSc, Medical Physics Department, International Oncotherapy Received: 6.02.2014 Centre Koszalin, Euromedic, 7 Chalubinskiego Str., 75-581 Koszalin, Poland, phone: 0048-94-711-13-02, Accepted: 13.04.2014 fax: 0048-94-711-13-03, e-mail: jkwg@wp.pl

Published: 26.06 .2014
} 
apy as monotherapy has been also published elsewhere $[3,11]$. For these reasons, in every case, an individual approach is needed [17].

\section{Case description}

The case of a 75-year-old male with multicentric lesions over the scalp in the temple and crown region is presented. The total tumor size was $15 \mathrm{~cm} \times 14 \mathrm{~cm}$. The biopsy from the one of the lesions has been taken and the rapid growth was observed. The shape of the tumor has changed to an ellipse and had spread from the left to the right temple. The color was dark brown, almost black, with papillary surface (Fig. 1). The biopsy diagnosis was angiosarcoma of the scalp with immunofenotype: CD31+, HHV8(-); Ki67 more than $20 \%$. The presence of distal metastasis was ruled out by an chest X-ray and abdominal ultrasound. Comorbidities included hypertension and left side paresis after cerebral stroke.

Taking into account general state, pathological examination, stage of the disease, and medical history, the patient was qualified for chemotherapy combined with brachytherapy. The first 8 of 10 cycles of pactitaxel (PXL) $75 \mathrm{mg} / 1 \mathrm{~m}^{2}$ every week has been given (Fig. 2). During chemotherapy, tumor size has decreased about $50 \%$. High-dose-rate brachytherapy followed chemotherapy in total dose of $30 \mathrm{~Gy}$ in 10 fractions during 12 days was applied treatment was accomplished with Flexitron HDR unit (Nucletron, an Elekta company, Elekta AB, Stockholm, Sweden). An individual mold applicator was made in the mold room (Fig. 3). The first step was to setup the patient in the repeated position during the whole treatment process. Patient was asked to lay on his back with the accessories to immobilize the body (AIO Base Plate with Head Support Short Neck With Flaps nr. 5, Head Support Normal No Flaps nr. 2, Head Support Pediatric With Flaps nr. 3; Orfit, Jericho, New York, USA). Next, the therapeutic region with the adequate defined margin with the wire-marker was marked on the scalp. A 3-pointed thermoplastic mask (3PT Head with Nose Efficast $2 \mathrm{~mm}$ max, Orfit) was prepared. An additional bolus ( $4.0 \mathrm{~mm}$ of the orfit) has been put on the mask. Afterwards, the therapeutic region was copied and marked on the mask. When the process of polymerization of orfit was finished, the flexible catheters (Best Medical International, Inc., Springfield, VA, USA) were fixed on the mask to cover the marked therapeutic region. 22 bronchial catheters were fixed parallel with the distance of

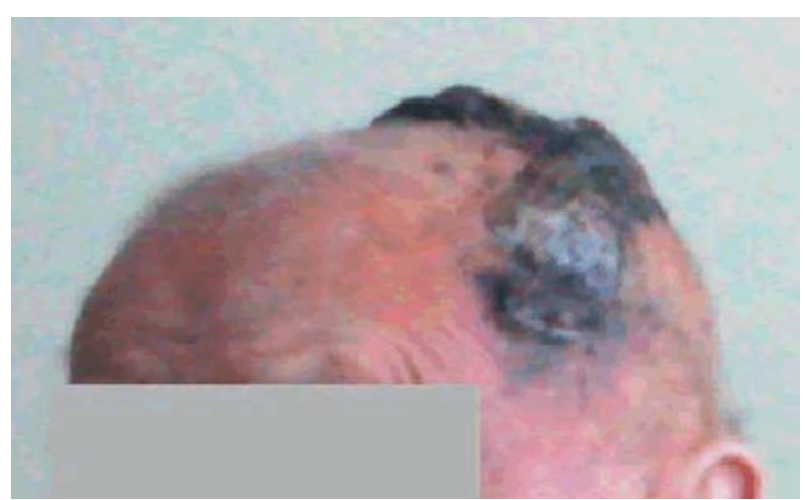

Fig. 1. The scalp during the waiting period for the histopathological examination

$1.0 \mathrm{~cm}$ to ensure adequate dose distribution, and to achieve satisfactory clinical target volume coverage. X-Ray markers (X-Ray Market Set, Nucletron, an Elekta company, Elekta $A B$, Stockholm, Sweden) were put inside the catheters in order to facilitate their reconstruction. Furthermore, characteristic points were marked on the skin and on the applicator. This allowed the applicator-patient position to be repeated. A computer tomography for patient with mold applicator, and with accessories for immobilizing the body was made the next day. CT slices equals to $3.0 \mathrm{~mm}$. Treatment plan was prepared with the Treatment Planning System Oncentra Brachy 4.0 (Nucletron, an Elekta company, Elekta $A B$, Stockholm, Sweden). The planning target volume (PTV) and critical organs (OARs) (lenses: left, right and brain) were defined and delineated. After the catheters reconstruction, the ${ }^{192}$ Ir source positions were generated to the target volume (Fig. 4). Reference lines were defined in the distance of $1.0 \mathrm{~cm}$ and $1.5 \mathrm{~cm}$ from the catheters, depending on the depth of the target. Target points were generated as well. The normalization and optimization to the target points was performed.

Cumulative dose volume histograms (DVH) are recommended for the evaluation of complex dose heterogeneity. DVH parameters were analyzed taking into account the minimum dose delivered to $90 \%$ and $100 \%$ of the target volume: $D_{90}, D_{100}$ and the volume, which is defined by $150 \%$ or $200 \%$ of the prescribed dose $\left(V_{150}, V_{200}\right)$. For the lenses, as critical organs, a maximum dose was considered $(0.1 \mathrm{cc})$. The dose distribution to target and critical organs was also analyzed on the CT scans (Fig. 5). The dose distribution is the result of a compromise between the target coverage, and the maximum doses of the lenses.

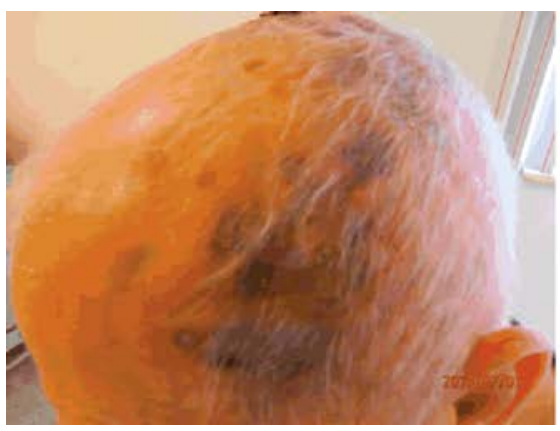

Fig. 2. The scalp after 8 doses of paclitaxel
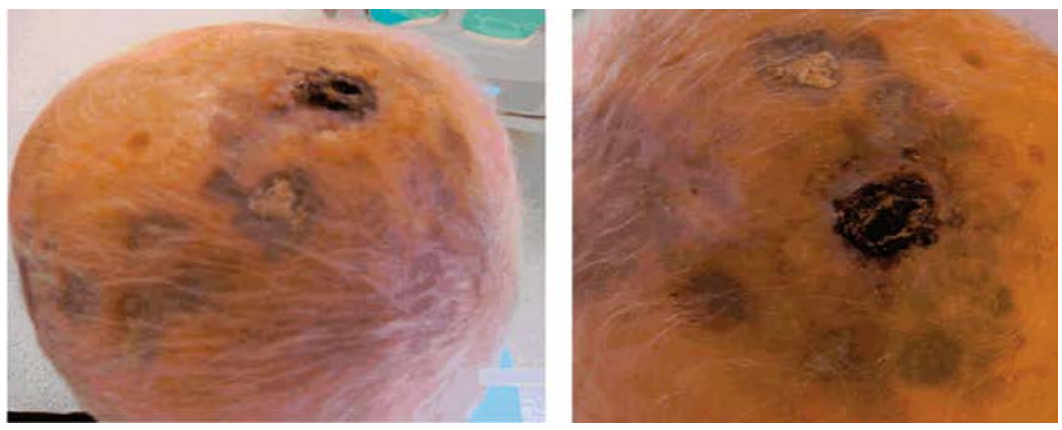


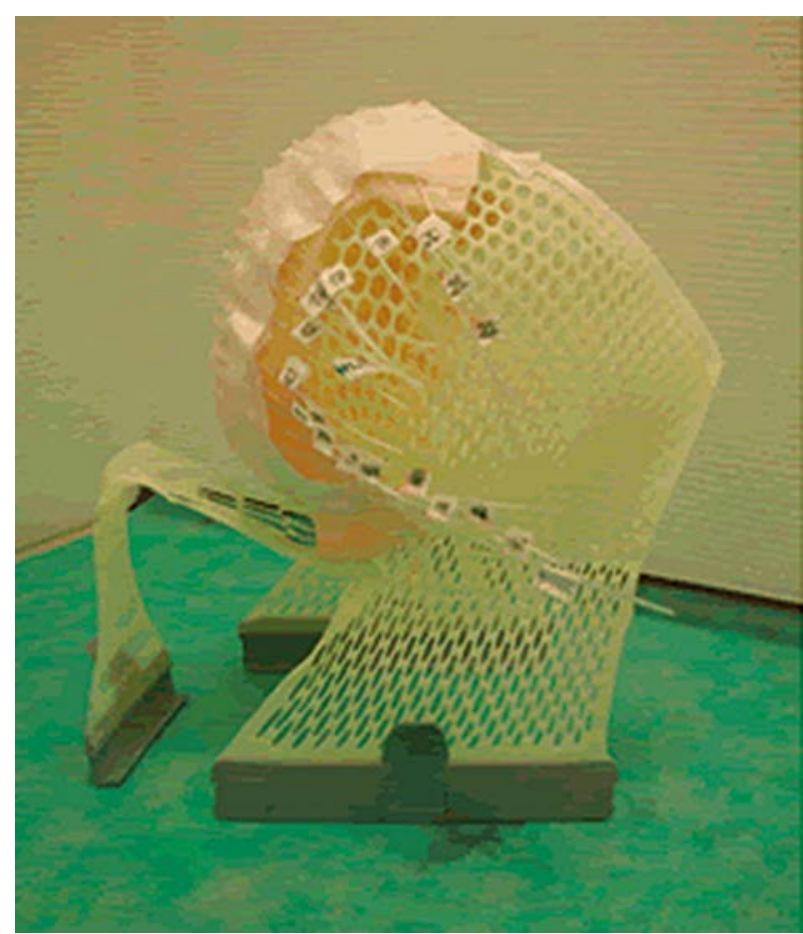

Fig. 3. The mold applicator

The following values for PTV were accepted: $\mathrm{V}_{100}=82.94 \%$ $(109.10 \mathrm{cc}), \mathrm{V}_{150}=4.27 \%$ (5.62 cc), $\mathrm{V}_{200}=0.49 \%$ (0.65 cc), $\mathrm{D}_{90}=2.77 \mathrm{~Gy} ; \mathrm{D}_{\text {ref }}=3 \mathrm{~Gy}$. The following values for the lenses were accepted: left 0.1-0.63 Gy, and right 0.1-0.51 Gy.

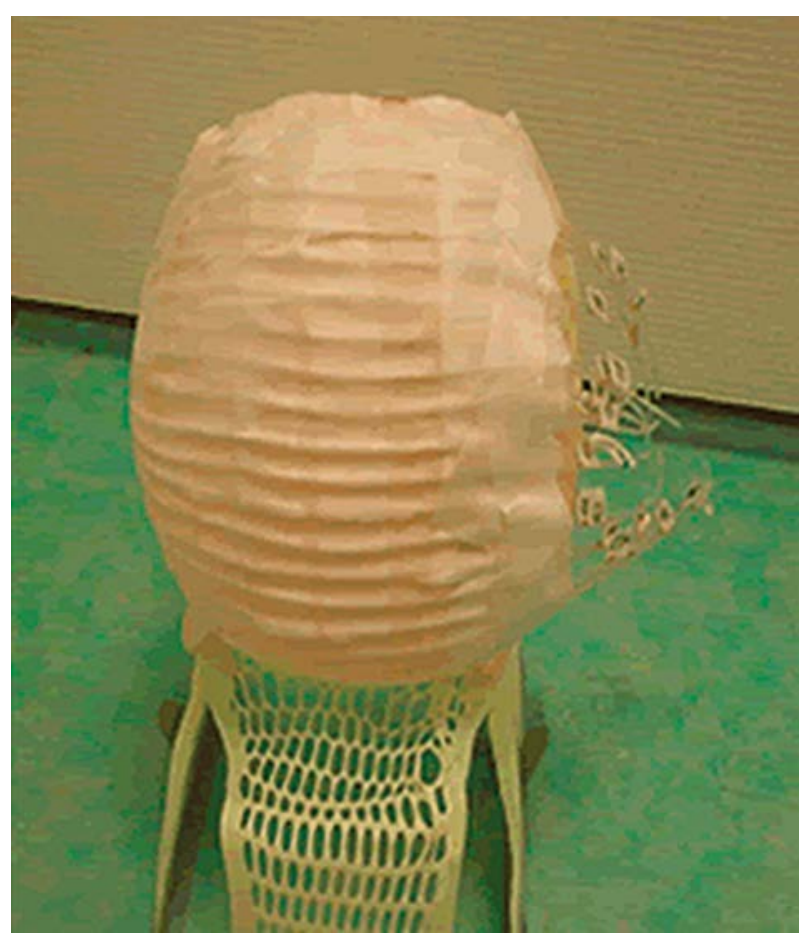

Because of the big curvatures of catheter's the pretreatment procedure has been performed. The mold applicator was connected with transfer tubes (Transfer Tubes Set, Nucletron, an Elekta company, Elekta AB, Stockholm,

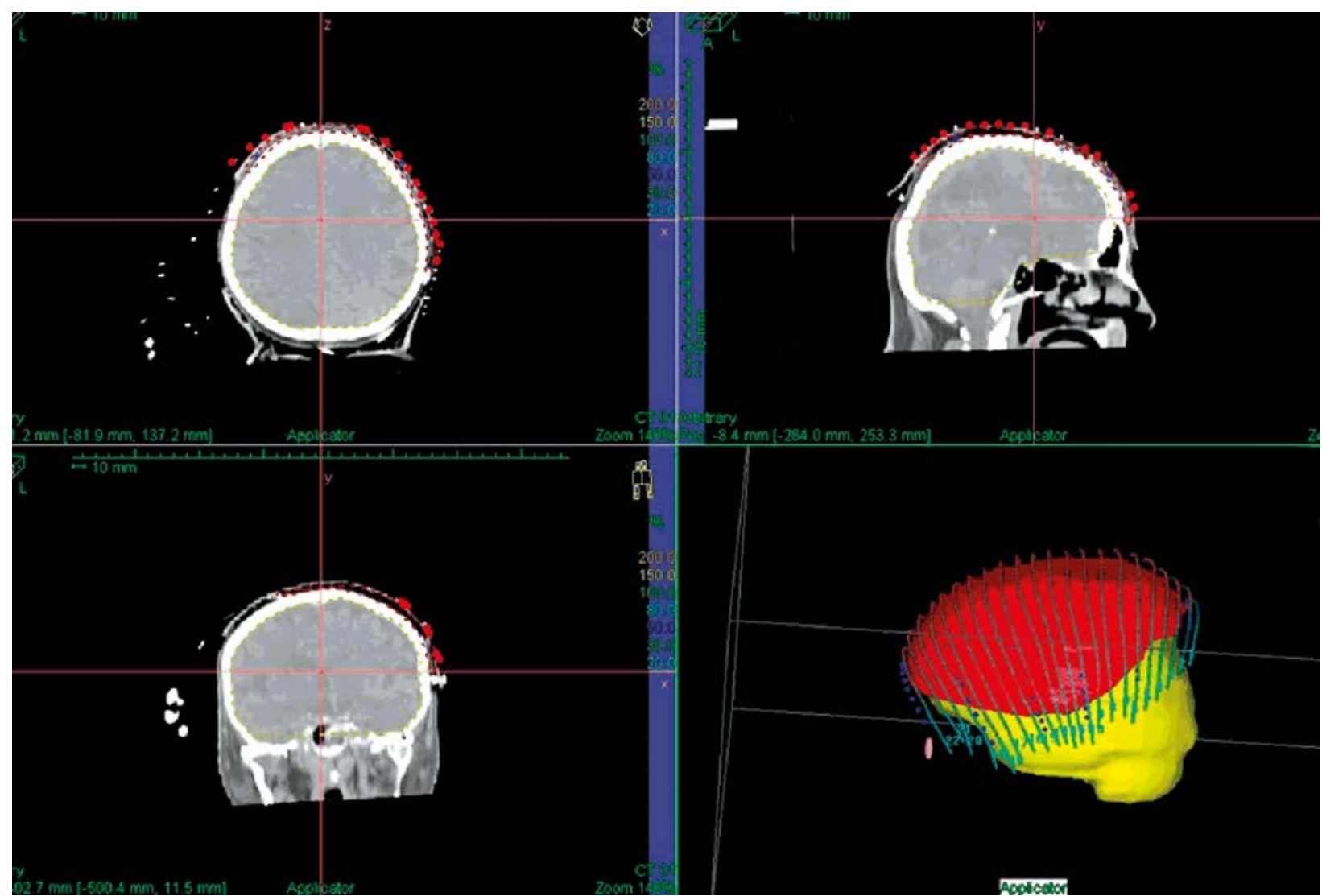

Fig. 4. Reconstruction of catheters 

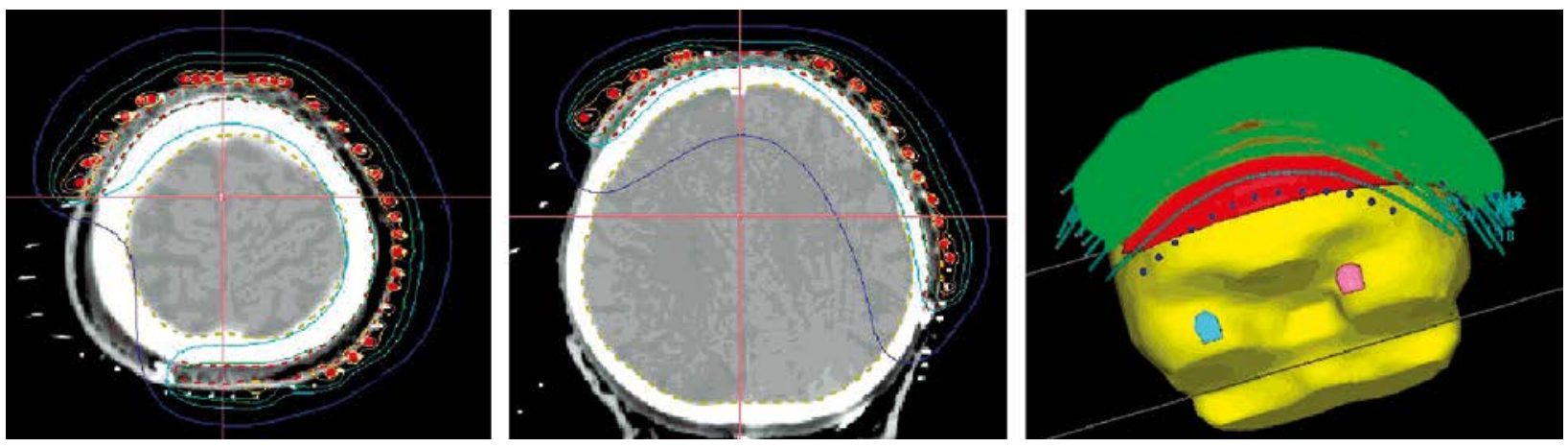

Fig. 5. Dose distribution: transversal CT scans and 3D view
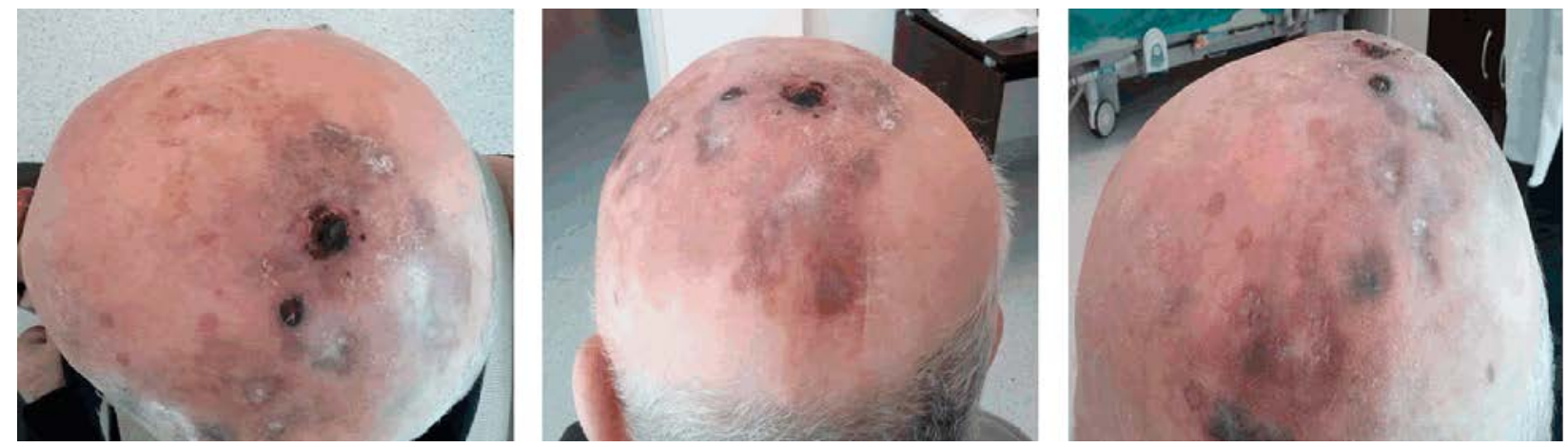

Fig. 6. The scalp 2 months after therapy

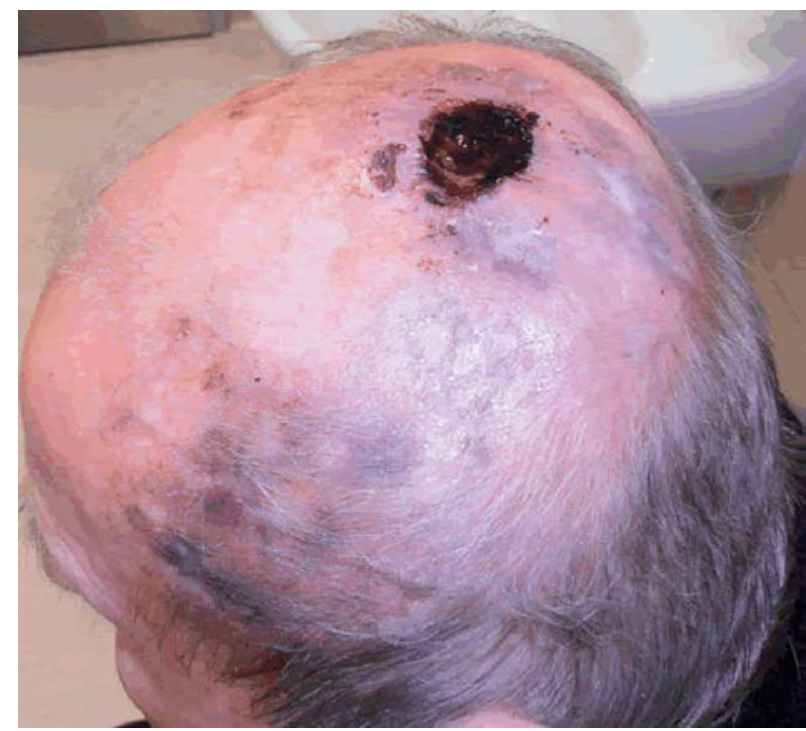

Fig. 7. The scalp 6.5 months after therapy

Sweden) to the Flexitron HDR unit. Afterwards, the treatment with patient started. No complications were reported during the treatment and the radiotherapy was well tolerated by the patient.

\section{Follow-up}

The scheme of follow-up was determined: the first control - in $3^{\text {th }}$ week after therapy, the second - in $6^{\text {th }}$ week. In the first year - every 2 months, in the second and third year - every 3 months. The fourth and the fifth year - every 6 months, and once a year after 5 years of treatment.

\section{Results}

During the follow-up examination in the $6^{\text {th }}$ week after brachytherapy, the partial remission of the tumor was observed. During the next follow-up examination ( 2 months after brachytherapy), local relapse on the scalp with 2 ulcerations: $1 \mathrm{~cm} \times 1 \mathrm{~cm}$ and $3 \mathrm{~cm} \times 3 \mathrm{~cm}$ size were observed (Fig. 6). Patient was qualified for palliative chemotherapy with gemcytabine: 12 cycles in 4 months with 7-10 days of intervals. Reduction of doses was necessary because of myelotoxicity. During the last follow-up visit (6.5 months after therapy), just one ulceration $3 \mathrm{~cm} \times 3 \mathrm{~cm}$ in the level of the skin was observed (Fig. 7). Chemotherapy will be continued depends of the personal tolerance and general patient condition.

\section{Discussion}

Sarcomas of soft tissue are uncommon malignances, and in each case, the personalization of interdisciplinary treatment ought to be done [1]. Mark et al. [2] presented only the group of 67 patients with angiosarcoma treated in four departments of Oncology in California during 35 years. This group was very heterogeneous, in aspects of localization of tumors, their stages, and treatment. The group of 48 patients with angiosarcoma of the scalp and face have been presented by Ogawa et al. [3]. All patients had external beam radiotherapy, some of them chemotherapy and surgery, but over $90 \%$ had treatment failure. Recently, brachytherapy was established as a useful component of treatment by American Brachytherapy Society [4]. Some authors described case reports with angiosarcoma of the face and scalp treatment with brachyther- 
apy, but there is no data describing the efficacy of this method in a larger group of patients $[8,11,16]$.

\section{Conclusions}

Chemotherapy with adjuvant radiation therapy may be a proposed scheme to treat inoperable angiosarcoma of the scalp. The mold HDR brachytherapy is an adequate, safe, practicable, and well tolerated by patients treatment method. Giving the effective results, HDR brachytherapy should be used as an adjuvant treatment after inoperable cases chemotherapy. In such kind of patients, in order to avoid a local relapse, the total dose increasing to $45 \mathrm{~Gy} /$ 15 fractions should be considered. On the other hand, it is always necessary to pay attention to critical organs protection. In described patient, the total given dose was limited by tolerance dose to the lenses. For these reasons, in every patient an individual approach is needed.

\section{Disclosure}

Authors report no conflict of interest.

\section{References}

1. Ruka W, Rutkowski P, Krzakowski M et al. Mięsaki tkanek miękkich u dorosłych - zasady postępowania diagnostycznoterapeutycznego. Onkol Prakt Klin 2009; 5: 198-210 [in Polish].

2. Mark RJ, Poen JC, Tran LM et al. Angiosarcoma. A report of 67 patients and a review of the literature. Cancer 1996; 77: 2400-2406

3. Ogawa K, Takahashi K, Asato Y et al. Treatment and prognostic of sarcoma of the scalp and face: a retrospective analysis of 48 patients. Br J Radiol 2012; 85: 1127-1133.

4. Holloway CL, DeLaney TF, Alektiar KM et al. American Brachytherapy Society (ABS) consensus statement for sarcoma brachytherapy. Brachytherapy 2013; 12: 179-190.

5. Maddox JC, Evans HL. Angiosarcoma of the skin and soft tissue: a study of forty four cases. Cancer 1981; 48: 1907-1921.

6. Jonska-Gmyrek J, Bakula-Zalewska E, Galecki J et al. Primary breast angiosarcoma in postmenopausal woman: case study and literature review. Prz Menopauzalny 2013; 17: 438-441.

7. Kamocki Z, Wilamowski R, Reszec J et al. Angiosarcoma of the large intestine - a case report. Contemp Oncol (Pozn) 2012; 16: 590-592.

8. DasDupta M, Chakrabarti N, Agrawal P et al. Angiosarcoma of the scalp. Indian J Plast Surg 2009; 42: 118-121.

9. Holden CA, Spittle MF, Jones EW. Angiosarcoma of the face and scalp, prognosis and treatment. Cancer 1987; 59: 1046-1057.

10. Baldini EH, Goldberg J, Jenner $C$ et al. Long term outcomes after function sparing surgery without radiotherapy for soft tissue sarcoma of the extremities and trunk. J Clin Oncol 1999; 17: 3252-3259.

11. Guix B, Finestres F, Tello J et al. Treatment of skin carcinomas of the face by high-dose-rate brachytherapy and custom-made surface moulds. Int J Radiat Oncol Biol Phys 2000; 47: 95-102.

12. Alektiar KM, Leung D, Zelefsky MJ et al. Adjuvant brachytherapy for primary high-grade soft tissue sarcoma of the extremity. Ann Surg Oncol 2002; 9: 48-56.

13. Wollina U, Fuller J, Graefe T et al. Angiosarcoma of the scalp: Treatment with liposomal doxorubicin and radiotherapy. J Cancer Res Clin Oncol 2001; 127: 396-399.

14. Ulrich L, Krause M, Brachmann A et al. Successful treatment of angiosarcoma of the scalp by intralesional cytokine therapy and surface irradiation. J Eur Acad Dermatol Venerol 2000; 14: 412-415.
15. Fata F, O'Reilly E, Ilson D et al. Paclitaxel in the treatment of patients with angiosarcoma of the scalp or face. Cancer 1999; 86: 2034-2037.

16. Nakamura R, Hanada S, Obara T et al. Iridium-192 brachytherapy for hemorrhagic angiosarcoma of the scalp: A case report. Jpn J Clin Oncol 2003; 33: 198.

17. Kowalik L, Lyczek J, Sawicki M et al. Individual applicator for brachytherapy for various sites of superficial malignant lesions. J Contemp Brachytherapy 2013; 5: 45-49. 